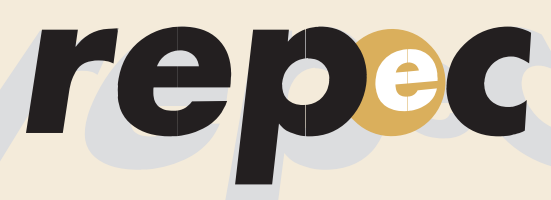

REPeC, Brasília, v. 9, n. 2, art. 5, p. 200-216, abr./jun. 2015

Disponível online em www.repec.org.br

DOI: http://dx.doi.org/10.17524/repec.v9i2.1180
Revista de Educação e Pesquisa em Contabilidade

Journal of Education and Research in Accounting

Revista de Educación e Investigación en Contabilidad

Periódico Trimestral, digital e gratuito publicado pela Academia Brasileira de Ciências Contábeis

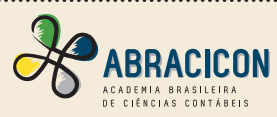

\title{
Níveis de Governança Corporativa da Bovespa e a Revelação de Informações ao Mercado: uma Comparação da Divulgação de Combinações de Negócios em Notas Explicativas
}

\begin{abstract}
Resumo
Neste trabalho, a revelação de informações associada à Governança Corporativa, a partir dos segmentos de listagem da Bolsa de Valores de São Paulo (Bovespa), é abordada pela divulgação de combinações de negócios nas demonstrações financeiras anuais. Com base no Pronunciamento Técnico CPC 15 , foram analisadas as notas explicativas das demonstrações de 2012 das empresas listadas na Bovespa, considerando os segmentos diferenciados de listagem, para investigar se os segmentos de maior nível de governança apresentariam também maior nível de divulgação. As informações publicadas foram analisadas quanto ao tipo: simples, descritivas e detalhistas, de maneira descritiva e com confirmação estatística, através dos testes de Mann-Whitney para comparação entre os segmentos de Novo Mercado e Mercado Tradicional e de Wilcoxon, para comparação dos blocos de informações. Não foram encontradas diferenças significativas no nível de divulgação atribuídas à governança, entretanto, constatou-se menor divulgação conforme maior a complexidade da informação requerida. Os resultados apontam para uma maior sensibilidade ao tipo de informação relacionada aos segmentos de listagem, uma abordagem aplicável a outros pronunciamentos normativos ou outros indicadores de Governança Corporativa.
\end{abstract}

Palavras-Chave: Combinações de Negócios; CPC 15; Segmentos de listagem.

\begin{abstract}
Ana Carolina Kolozsvari Bacharel em Ciências Contábeis Faculdade Moraes Júnior - Mackenzie Rio e Mestranda em Ciências Contábeis na Universidade Federal do Rio de Janeiro (UFRJ). Contato: Av. Pasteur, 250, Urca, Rio de Janeiro, RJ. CEP.: 22290-250.

E-mail: anacko@gmail.com
\end{abstract}

\section{Adriano Rodrigues}

Doutor em Controladoria e Contabilidade pela Universidade de São Paulo (USP) e Professor da Universidade Federal do Rio de Janeiro (UFRJ). Contato: Av. Pasteur, 250, sala 250, Urca, Rio de Janeiro, RJ. CEP.: 22290-250.

E-mail: adriano@facc.ufrj.br 


\section{Introdução}

Operações de fusões e aquisições de empresas motivam pesquisas tanto pela natureza das negociações como pela magnitude das transações. Entre as diversas possibilidades jurídicas de restruturação societária, existem as que provocam alteração no controle de sociedades. Essas, em essência, são operações de combinações de negócios, em que há especial interesse de estudo contábil. Conforme defendem Iudícibus, Martins, Gelbcke e Santos (2010), "uma combinação de negócios é um evento relevante a ponto de alterar a base de avaliação dos ativos e passivos das entidades ou negócios adquiridos". Dessa forma, trata-se de uma operação com consequências contábeis, tanto para a adquirida quanto para a adquirente do negócio.

A divulgação das combinações de negócios nas informações financeiras também se faz relevante quanto à recepção pelo mercado. Em 2012, foram publicadas mais de 400 demonstrações financeiras, entre as quais foram identificadas quase 100 divulgações de combinações de negócios. Como são operações societárias que promovem alterações na estrutura de controle das empresas, trata-se de informações particularmente úteis no processo decisório de usuários externos. Em compromisso com maior nível de transparência corporativa, a Bolsa de Valores de São Paulo (Bovespa) possui segmentos especiais de listagem, de adesão voluntária, adequados aos diferentes perfis de empresas, com rígidas regras de governança, que atraem os investidores. Assim, são assegurados direitos e garantias aos acionistas, bem como a divulgação de informações mais completas aos participantes de mercado (Bovespa, 2013b).

Quanto aos segmentos especiais de listagem da bolsa, Novo Mercado, Nível 2 e Nível 1; o Novo Mercado, segundo a Bovespa (2013a), é considerado o padrão de transparência e governança exigido pelos investidores, com práticas de governança adicionais às exigidas pela legislação brasileira e de divulgação de informações mais transparentes e abrangentes. Em contrapartida, conforme conta o Instituto Brasileiro de Governança Corporativa (IBCG) (2013), é característica do mercado brasileiro uma alta concentração do controle acionário, uma baixa efetividade dos conselhos de administração e alta sobreposição entre propriedade e gestão, o que aponta para um menor interesse das empresas em fornecer informações ao mercado de forma transparente.

Nesse contexto, cabe a pergunta de pesquisa: $\mathbf{O}$ nível de Governança Corporativa representado pela adesão aos segmentos especiais de listagem da Bovespa, influencia na divulgação de informações estratégicas para o mercado, como combinações de negócios? O objetivo desta pesquisa consistiu em investigar o nível de divulgação das informações de combinações de negócios nas demonstrações financeiras das empresas de capital aberto listadas na Bovespa, em relação ao ano de 2012, considerando os diferentes segmentos de mercado.

Estudos anteriores mostram que, quando considerada a evidenciação de informações voluntárias pelas empresas, os segmentos especiais de listagem são fatores determinantes no nível de divulgação de informações, conforme os estudos de Lanzana, Silveira e Famá (2006), Murcia e Santos (2009), Mendes-da-Silva, Ferraz-Andrade, Famá e Maluf (2009). Já quando analisada a divulgação das informações relacionada às combinações de negócios no âmbito da nova norma contábil CPC 15 - Combinação de Negócios, de caráter obrigatório, tal estratificação não se mostra relevante, de acordo com Nakayama (2012), Bachir (2013), Assis, Marinho, Silva e Andrade (2013) e Nakayama e Salotti (2014). Entretanto, tais pesquisas compreenderam os anos de 2010 e 2011 e associaram à falta do completo cumprimento da norma sua novidade, indicando possivelmente uma curva de aprendizado pelas empresas, de forma que passaria a ser esperado que, em anos seguintes, o amadurecimento dos preparadores da informação promovesse a divulgação das informações completas.

Por serem informações de divulgação obrigatória ainda não completamente absorvidas pela prática contábil, e a norma ter sido adotada há alguns exercícios, é pertinente esperar que comecem a emergir diferenças no nível de divulgação entre as empresas. Como reflexo dos compromissos adicionais de divulgação pela adesão dos segmentos especiais, e, portanto, maior interesse na divulgação completa das informações, conforme argumenta a Bovespa (2013c), em comparação ao mercado tradicional brasileiro descrito pelo IBCG (2013), pela hipótese principal desta pesquisa, espera-se encontrar um maior nível de divulgação de informações sobre combinação de negócios das empresas pertencentes ao Novo Mercado em relação às do Mercado Tradicional. 
Atualmente, a norma que regulamenta a divulgação das combinações é o Pronunciamento Técnico CPC 15 (R1) - Combinação de Negócios, de 2011. Para análise do nível de divulgação das combinações de negócios realizadas, foi elaborada uma lista com itens não condicionais a serem informados sobre as operações, e observadas as publicações nas notas explicativas das demonstrações financeiras anuais. A lista foi elaborada com o propósito de medir diferentes níveis de atendimento ao pronunciamento: informações mais simples e diretas sobre as operações; informações qualitativas, de caráter descritivo; e informações sobre detalhes financeiros e contábeis, consideradas mais complexas. Em hipótese adicional à pesquisa, espera-se encontrar um maior nível de divulgação de informações mais simples e menor nível de divulgação, conforme maior a complexidade da informação requisitada.

Pelo agrupamento das empresas quanto aos segmentos de listagem, e das informações quanto ao tipo de requisição normativa, foram encontradas evidências de sensibilidade quanto ao tipo de informação reportada, ainda que não se tenham encontrado evidências significativas de maior divulgação associada aos níveis de governança corporativa utilizados nesta pesquisa em caráter geral. Com isso, espera-se contribuir na evidenciação de diferentes níveis de divulgação de informações pelas empresas, associada ao tipo de informação requerida pela norma e a divulgada pelas empresas.

Na próxima seção são apresentados os fundamentos teóricos sobre operações de combinação de negócios e divulgação de informações associada à Governança Corporativa, representada pelos segmentos especiais de listagem da bolsa. A metodologia aborda o levantamento dos dados, com a apresentação dos requisitos analisados, e testes estatísticos pertinentes. Em seguida é apresentada a análise dos resultados e, por fim, se conclui.

\section{Fundamentação Teórica}

Combinações de negócios são operações cuja divulgação é atualmente regulamentada pelo Pronunciamento Técnico CPC 15 (R1) - Combinação de Negócios, de 2011, correspondente ao IFRS 3 - Business Combinations (International Accounting Standards Board [IASB], 2011). De acordo com o pronunciamento, uma combinação de negócios é "uma operação ou outro evento por meio do qual um adquirente obtém o controle de um ou mais negócios, independentemente da forma jurídica da operação", incluindo fusões entre partes independentes. O termo "negócio" é definido como "um conjunto integrado de atividades e ativos capaz de ser conduzido e gerenciado para gerar retorno, na forma de dividendos, redução de custos ou outros benefícios econômicos, diretamente a seus investidores ou outros proprietários, membros ou participantes". A definição de controle é dada por: "poder para governar a política financeira e operacional da entidade de forma a obter benefícios de suas atividades".

A entidade que obtém o controle é tratada por adquirente, e o negócio cujo controle é obtido, por meio da operação, é a adquirida. Na apresentação do escopo do pronunciamento, observa-se que quando o controle é compartilhado, caso das joint ventures, deve ser atendido ao Pronunciamento Técnico CPC 19 (R1) - Investimento em Empreendimento Controlado em Conjunto, e não se aplica o CPC 15 (R1) Combinação de Negócios. É importante destacar que, para ser considerada uma combinação de negócios, deve haver transferência de controle. Iudícibus et al. (2010) observam que operações de restruturação societária em que as entidades permanecem sob o mesmo controle não constituem combinações de negócios para fins contábeis, uma vez que não há a figura da transferência de controle.

Em conformidade com o CPC 15 (R1), itens 4 e 5, na combinação de negócios, o negócio adquirido deve ser avaliado pelo método de aquisição. Para sua aplicação, deve ser identificado o adquirente do negócio e determinada a data de aquisição. Também devem ser reconhecidos e mensurados: os ativos identificáveis adquiridos, os passivos assumidos, e as participações societárias de não controladores na adquirida; o ágio por expectativa de rentabilidade futura ( $g o o d w i l l)$ ou o ganho por compra vantajosa.

De forma geral, as informações sobre as combinações de negócios a serem divulgadas constam no item B64 do Pronunciamento Técnico CPC 15 (R1) - Combinação de Negócios (2011). Os requisitos de divulgação são compostos por itens incondicionais, que não dependem de fatores específicos da opera- 
ção, e por itens condicionais, aplicáveis apenas a determinados casos. Assim, sempre deverão constar informações de caráter incondicional como nome da empresa adquirida, data e motivos da aquisição. Em contrapartida, informações como participações de não controladores não são pertinentes para casos de aquisição da totalidade do negócio, em que há apenas a figura do controlador, e são, portanto, condicionais.

Em Bachir (2013), foram analisadas as demonstrações de 2010 e 2011, a partir de uma lista de requisitos composta por sete itens incondicionais, e uma das constatações do autor foi a de que há menor divulgação conforme mais complexa a informação. Uma consideração importante utilizada na pesquisa foi que a escolha dos itens não condicionais permite uma análise comparativa de frequência das informações constantes nas demonstrações analisadas de forma conjunta. Por outro lado, foram selecionados itens diretamente do CPC 15, sem segregação de itens compostos, de forma que, quando atendidos apenas parcialmente, o julgamento do autor foi de considerar o não atendimento do requisito.

Em Nakayama (2012) e Nakayama e Salotti (2014), foram analisadas as demonstrações de 2010, para observar quais fatores influenciaram o nível de divulgação das empresas, construindo um índice de disclosure de operação de combinação de negócios, baseado no trabalho de Shalev (2009). Destaca-se que os autores entendem esse disclosure como um nível de compliance das empresas com as normas, por se tratar de itens que são exigidos e, não, de divulgação voluntária. Entre os fatores analisados, concluiu-se serem relevantes para o índice, o porte da empresa de auditoria e o porte relativo da empresa adquirida em relação à adquirente, enquanto a listagem nos segmentos Nível 2 ou Novo Mercado foi revelada não significativa para o modelo. Assis et al. (2013) realizaram uma pesquisa nos relatórios das empresas apenas do Novo Mercado, para o ano de 2011, a partir da mesma lista elaborada por Nakayama (2012), e observaram que não houve evolução significativa de um ano para o outro.

Em um estudo no mercado americano, Shalev (2009) verificou o disclosure das combinações com foco sobre o valor goodwill na operação. Os resultados mostraram que o nível de informação divulgada diminuiu conforme maior o goodwill, sugerindo que as empresas tendem a uma menor divulgação conforme a aquisição seja menos favorável. Vale comentar que em Nakayama (2012) e Nakayama e Salotti (2014), para o Brasil, o goodwill não se apresentou como fator relevante para explicar o índice de disclosure.

Sob a perspectiva de que a divulgação de um maior nível de informações permite uma avaliação mais precisa das empresas, Hodgdon, Tondkar, Harless e Adhikari (2008) mensuram o comprometimento de uma amostra de empresas, principalmente da Suíça e Alemanha, com os requerimentos dos IFRS em relação às avaliações realizadas por analistas do mercado. Os resultados corroboram a importância do disclosure para a acurácia das análises, e os autores enfatizam o comprometimento na divulgação das informações como tão importante quanto a própria normatização em si.

Para o mercado brasileiro, Murcia e Santos (2009) analisaram as informações financeiras de 2007 das 100 maiores empresas listadas na Bovespa e observaram que o índice de disclosure desenvolvido pelos autores mostrou relação positiva com o setor de atuação, tamanho, presença na bolsa de Nova Iorque e presença nos segmentos de listagem diferenciados da bolsa. Esses últimos dois fatores são associados à hipótese do vínculo (bonding hypothesis) pelos autores, que considera que empresas localizadas em países com fracos arcabouços institucionais são levadas a buscar mecanismos adicionais para mostrar confiança aos investidores e obter financiamentos externos, conforme explica Leuz (2006). Assim, a adesão aos segmentos especiais de listagem da Bovespa refletiria o compromisso de maior transparência e melhores práticas de disclosure. Outro trabalho que associa à presença nos segmentos especiais a um maior nível de disclosure, foi Mendes-da-Silva et al. (2009), com relação à divulgação de informações em websites, ainda que não existisse padronização para uso da internet na comunicação com investidores.

Quanto ao nível de disclosure das empresas relacionado à Governança Corporativa, Lanzana et al. (2006) apresentam um estudo que aponta para uma relação de complementaridade: empresas com melhor estrutura de governança apresentam maior nível de disclosure. Para a pesquisa, foram utilizadas cinco variáveis independentes de governança, relacionadas à estrutura de propriedade e ao conselho de administração. O contexto do trabalho dos autores reflete uma realidade do mercado brasileiro em que há forte concentração das ações com direito a voto, somado a um alto índice de emissão de ações sem direito a voto. 
Rabelo, Rogers, Ribeiro e Securato (2007) testaram empiricamente os retornos fornecidos para o acionista de dois tipos de carteiras de ações: com empresas listadas e com empresas não listadas nos segmentos especiais. Os autores mostram que há indícios de que o desempenho das carteiras formadas com empresas dos segmentos especiais é melhor em relação ao desempenho das empresas do mercado tradicional.

Em abordagem semelhante, Sirqueira, Kalatziz e Toledo (2007) também verificaram maior retorno em uma carteira formada com práticas de governança diferenciadas, em relação a uma carteira com empresas que não adotam tais práticas. Conforme argumentam os autores, a Governança Corporativa consiste em, entre outras práticas, medidas que busquem aumentar a transparência e prestação de contas, que permitem redução na assimetria de informação. Isso possibilita maior comparação das empresas pelos investidores, notando que os pequenos "são prejudicados pela falta de transparência da divulgação de informações".

O Instituto Brasileiro de Governança Corporativa contribui com seu Código das Melhores Práticas de Governança Corporativa (IBCG, 2009) em reforço para evidenciar a relevância do tema. Conforme o documento, as boas práticas convertem princípios em recomendações objetivas, de forma a alinhar interesses otimizando o valor da organização, constituídos de transparência, equidade, prestação de contas e responsabilidade corporativa.

Adicionalmente, o IBCG (2013) monta uma perspectiva histórica de processos de globalização, privatização e desregulamentação da economia que culminam em um cenário de ambiente corporativo competitivo. O Instituto destaca a reformulação da Lei das Sociedades por Ações, a cartilha da Comissão de Valores Mobiliários (CVM) para orientar o relacionamento entre administradores, acionistas, auditores; a criação dos segmentos especiais de listagem da Bovespa; e as premiações do próprio Instituto, como contribuições para estimular a disseminação e a aplicabilidade das práticas de Governança Corporativa. Apesar do aprofundamento dos debates alcançados, o Instituto pondera que no Brasil ainda há alta concentração de controle acionário, baixa efetividade dos conselhos de administração e alta sobreposição entre propriedade e gestão e conclui que há "vasto campo para o incentivo ao conhecimento, ações e divulgação dos preceitos de governança corporativa”. (IBCG, 2013)

Via de regra, estudos sobre disclosure tratam de divulgação voluntária de informações realizadas pelas empresas. Esta pesquisa trata do atendimento aos requisitos do CPC 15 (R1) que, entre outros aspectos, normatiza sobre a divulgação obrigatória de informações sobre combinações de negócios realizadas. Esta diferença levanta um contra-argumento à hipótese da pesquisa que também a motiva, pois poderia se considerar que, como a divulgação de acordo com o pronunciamento técnico é obrigatória, não deveriam ser encontradas diferenças entre as empresas quanto ao nível de divulgação.

Entretanto, resultados dos estudos anteriores considerados, especialmente Bachir (2013), Nakayama (2012), Nakayama e Salotti (2014) e Assis et al. (2013), mostram divulgação incompleta das informações sobre esse pronunciamento técnico específico. Nakayama (2012) e Nakayama e Salotti (2014) propõem que o nível de disclosure pode ser usado para mostrar o compliance das empresas com as normas, dado que os itens são de divulgação obrigatória.

Como concluem os autores desses trabalhos, há a possibilidade de que uma curva de aprendizado, devido à novidade da norma, promova um maior nível de divulgação, conforme se decorrerem os exercícios sociais. Frente a essa perspectiva, e pelo fato de que as empresas listadas nos segmentos especiais possuem compromissos adicionais de divulgação de informações, é possível argumentar que surjam diferenças no nível de divulgação obrigatória das combinações de negócios relacionadas à presença nos segmentos especiais de listagem. Além disso, conforme Bachir (2013) observa, os requisitos de divulgação possuem características distintas, o que permite seu agrupamento. Com isso, tem-se a possibilidade de investigação de diferenças quanto ao nível de divulgação relacionado ao tipo de informação requerida, algo não identificado em estudos anteriores. Com base nessas ponderações, foram delineados os procedimentos metodológicos, descritos na próxima seção. 


\section{Metodologia}

Conforme a tipologia oferecida por Raupp e Beuren (2010), esta pesquisa pode ser classificada como descritiva quanto aos objetivos, por buscar comparar os níveis de divulgação de combinações de negócios nas notas explicativas das empresas quanto ao seu nível de Governança Corporativa e complexidade das informações. Como bibliográfica e documental, quanto aos procedimentos, por utilizar referências já trabalhadas de estudos anteriores buscando organizar informações dispersas como as informações divulgadas pelas empresas. E como quantitativa, quanto à abordagem do problema, observando o comportamento geral com emprego de instrumentos estatísticos para maior fundamentação das observações.

Nesta pesquisa, buscou-se observar o atendimento aos requisitos do CPC 15 (R1) - Combinação de Negócios de itens não condicionais, para comparação da divulgação das informações entre as empresas, associando-as quanto ao segmento de mercado. A lista das empresas a serem consultadas foi obtida a partir da base de dados disponível no site da Bovespa, considerando-se o nível de Governança Corporativa, de acordo com o segmento de listagem. A composição das empresas cujas notas explicativas foram analisadas consistiu em: 130 empresas no Novo Mercado; 21 empresas no Nível 2 de Governança Corporativa; 32 empresas no Nível 1; e 258 empresas no Mercado Tradicional. No total, foram analisadas as notas explicativas de 441 empresas.

Como as pesquisas recentes de Nakayama (2012), Assis et al. (2013), Bachir (2013) e Nakayama e Salotti (2014) abordaram os anos de 2010 e 2011, encontrando níveis de divulgação considerados baixos pelos autores, ao que atribuíram à novidade da norma, optou-se pela análise de informações mais recentes para a realização desta pesquisa, o ano de 2012. Com isso, pretendeu-se manter maior distanciamento deste possível fator de influência sobre a divulgação de informações demandadas pela normatização em notas explicativas.

Uma das considerações realizadas para a observação da divulgação das informações foi a de manter apenas itens incondicionais, ou seja, que não dependem de fatores específicos de operações realizadas. Isso permite uma comparabilidade entre as práticas adotadas pelas empresas, por considerar apenas itens de divulgação obrigatória em todos os casos, mesmo quando considerados em conjunto, como no caso do item de goodwill associado à compra vantajosa. Como em alguns casos o pagamento é o próprio valor justo, estipulou-se que a empresa deveria informar que não foram apuradas diferenças, de forma a manter este item como único e incondicional.

Outra consideração relevante foi a de individualizar itens compostos, para que se permitisse uma avaliação de atendimento parcial a determinado item do pronunciamento. Por exemplo, o item B64 (a) do CPC 15 (R1) foi separado em dois: o nome da adquirida em um bloco de informações mais diretas sobre a operação, e a descrição da adquirida, em um bloco sobre informações qualitativas, com caráter descritivo. Isto permitiu mensurar que o nome da adquirida foi sempre divulgado, embora nem sempre tenha sido apresentada uma descrição sobre o negócio que foi adquirido. 


\begin{tabular}{|cl|}
\hline \multicolumn{1}{|c|}{ Grupo 1: Informações simples e diretas sobre a operação } \\
\hline A & Nome da empresa adquirida \\
B & Data da operação \\
C & Parcela adquirida, com percentual do capital \\
D & Valor justo da contraprestação total \\
\hline \multicolumn{1}{c|}{ Grupo 2: Informações qualitativas, com caráter descritivo } \\
\hline E & Descrição da empresa adquirida \\
F & Motivos ou objetivos da aquisição, como vantagens competitivas \\
G & Descrição do processo de aquisição do controle \\
H & Fundamentação qualitativa de ágio ou da compra vantajosa \\
\hline & $\quad$ Grupo 3: Informações sobre os detalhes financeiros e contábeis das operações \\
\hline I & Valor justo dos tipos mais relevantes de contraprestação \\
J & Montante reconhecido das principais classes de ativos adquiridos e passivos assumidos \\
K & Receita e resultado gerados pela adquirida desde a aquisição \\
L & Receita e resultado que teriam sido gerados pela adquirida desde o início do exercício \\
\hline
\end{tabular}

Figura 1. Itens analisados na composição de cada grupo

Fonte: elaborado pelos autores.

Além da normatização do CPC 15 (R1), foram considerados os argumentos e os itens das listas elaboradas por Nakayama (2012) e Bachir (2013) para determinação dos quesitos a serem avaliados, resultando em um total de 12 itens, que podem ser divididos em três grupos, buscando medir diferentes dimensões de informação. No Grupo 1, foi observada a divulgação de informações simples e diretas, relacionadas a um nível mais geral sobre a operação. No Grupo 2, buscou-se identificar informações qualitativas, com caráter descritivo. E no Grupo 3, foram alocadas as informações consideradas mais complexas, relacionadas a detalhes financeiros e contábeis. Os itens são apresentados na Figura 1.

A partir da lista de requisitos, foram analisadas as informações divulgadas nas notas explicativas das demonstrações financeiras de 2012, a partir do banco de dados disponível no site da CVM. Buscou-se identificar a realização de combinações de negócios divulgadas nestas notas explicativas, em que se procurou pela utilização de termos como "combinação" ou "combinações". Procurou-se, também, por termos como "aquisição", "aquisições", "controle", "controlada" e semelhantes. Foram analisadas descrições de contexto operacional e de fatos relevantes, apresentadas no início das notas explicativas; proporções de participação em capital de controladas, quando são apresentadas as bases de consolidação das demonstrações; e informações específicas sobre investimentos, em nota explicativa específica. Por fim, quando não foram identificadas combinações de negócios de forma explícita, buscou-se por meio da inspeção geral das notas explicativas, principalmente quando divulgadas operações de restruturação societária.

Como foi utilizada a técnica de inspeção documental, há limitações inerentes a esse procedimento. Observou-se que nem sempre todos os itens foram apresentados juntos em uma nota explicativa separada, o que requer uma procura pelo documento como um todo. Assim, há possibilidade de a combinação de negócios ser informada em diversos pontos separados, por exemplo: descrição da aquisição quando se relatam os fatos relevantes no início das notas explicativas, alterações de participações quando são apresentadas as empresas controladas para a consolidação, descrição das empresas controladas e seus valores em item de investimentos e detalhamento de ágio em item de intangíveis. Dessa forma, algum requisito que tenha sido divulgado pode vir a ter passado despercebido, influenciando na avaliação de determinada empresa. Entretanto, como padrão geral, encontrou-se a divulgação das informações juntas: normalmente aparecem em nota explicativa específica para combinação de negócios, ou em conjunto com investimentos, ou ainda descritas como acontecimentos relevantes. Dessa forma, considera-se que possíveis situações pontuais não venham a distorcer de forma relevante os resultados obtidos e as conclusões da pesquisa. 
A partir da identificação da publicação de combinações de negócios, foi possível analisar as informações divulgadas em relação a cada item. Quando a informação se mostrou presente, foi atribuído o valor 1; quando ausente, atribuiu-se o valor 0. Do total de 441 empresas, obtiveram-se 53 empresas que divulgaram terem realizado combinações de negócios em 2012, em 94 operações. Os resultados apresentados na próxima seção são analisados quanto ao total de operações divulgadas.

Convém acrescentar que, por vezes, foram encontrados níveis diferentes de divulgação sobre operações distintas nas notas explicativas de uma mesma empresa. Além disso, determinadas operações foram publicadas por mais de uma empresa, por exemplo, quando empresas cujas controladas também possuíam capital aberto e realizaram combinações de negócios, a operação foi reportada em ambas as demonstrações. Embora isso faça com que não se reflita a quantidade exata de operações que ocorreram no ano, o objeto do estudo foca nas publicações das operações das empresas de capital aberto em notas explicativas das demonstrações de 2012.

Em abordagem incremental à análise descritiva da frequência da divulgação dos itens analisados, foram realizados testes estatísticos para verificar se as frequências seriam iguais ou diferentes, tanto entre os segmentos de mercado quanto entre os blocos de informações. Pela consideração da natureza dos dados - a frequência de divulgação de poucos itens; e da baixa quantidade de observações, optou-se pela realização de testes não paramétricos.

Como na hipótese principal espera-se encontrar que no Novo Mercado a frequência de divulgação das informações seja maior que no Mercado Tradicional, é pertinente aplicar o teste de Mann-Whitney, para duas amostras independentes. De acordo com Fávero, Belfiore, Silva e Chan (2009), testes desse tipo não requerem que as amostras sejam do mesmo tamanho, e a única exigência do teste de Mann-Whitney é que a variável seja pelo menos ordinal. Na investigação da hipótese principal da pesquisa, um resultado estatístico que aponte para a rejeição do teste de Mann-Whitney confirma a hipótese da pesquisa, quando indicar uma frequência estatisticamente superior das informações no Novo Mercado em comparação ao Mercado Tradicional. Esse teste também foi realizado para comparar os dois segmentos em relação aos blocos de informações isolados, como forma de investigar diferenças estatísticas entre os níveis de governança em relação a cada tipo de informação.

Já na hipótese adicional, espera-se encontrar maiores frequências de divulgação para informações mais simples e menores frequências, conforme maior a complexidade da informação. Nesse caso, foi aplicado o teste de Wilcoxon, para amostras emparelhadas, dado que a comparação é realizada entre os blocos de informações das mesmas empresas. De acordo com Fávero et al. (2009), esse teste trabalha com a informação sobre a direção das diferenças de cada par e a magnitude da diferença dentro dos pares, e sua hipótese nula afirma não haver diferenças entre as amostras. Ou seja, pela a aplicação do teste Wilcoxon, busca-se verificar diferenças estatisticamente significativas entre as frequências de divulgação dos blocos de informações no conjunto das empresas como um todo, e também dentro de cada segmento de mercado. 


\section{Resultados e Análises}

O conjunto das empresas foi segmentado de acordo com os níveis de listagem especial da Bovespa, obtendo-se quatro grupos. O levantamento das quantidades e proporções das operações divulgadas de acordo com cada segmento de mercado é apresentado na Tabela 1 .

Tabela 1

Quantidade de empresas e combinações divulgadas quanto ao segmento do mercado

\begin{tabular}{lrrrrrr}
\hline $\begin{array}{c}\text { Segmento do } \\
\text { Mercado }\end{array}$ & $\begin{array}{c}\text { Quantidade de empresas } \\
\text { em cada segmento }\end{array}$ & $\begin{array}{c}\text { Empresas que divulgaram a } \\
\text { realização de combinações } \\
\text { de negócios }\end{array}$ & $\begin{array}{c}\text { Quantidade de combinações } \\
\text { de negócios divulgadas }\end{array}$ \\
\hline Novo Mercado & 130 & $29 \%$ & 32 & $60 \%$ & 56 & $60 \%$ \\
\hline Nível 2 & 21 & $5 \%$ & 4 & $8 \%$ & 8 & $9 \%$ \\
\hline Nível 1 & 32 & $7 \%$ & 8 & $15 \%$ & 8 & $9 \%$ \\
\hline Mercado Tradicional & 258 & $59 \%$ & 9 & $17 \%$ & 22 & $23 \%$ \\
\hline Total & 441 & $100 \%$ & 53 & $100 \%$ & 94 & $100 \%$ \\
\hline
\end{tabular}

Fonte: elaborado pelos autores.

Uma maior proporção de divulgação de combinações é observada no Novo Mercado, embora a maior parte das empresas seja pertencente ao Mercado Tradicional. Os segmentos intermediários, Nível 1 e Nível 2, apresentam baixa quantidade de empresas atuantes em relação ao mercado total, e a quantidade de operações divulgadas, frente ao total de operações, também são os menores.

Pela análise das notas explicativas das demonstrações financeiras das empresas, foi possível determinar a presença, ou não, das informações em relação aos critérios de divulgação considerados. Conforme descrito na metodologia, foi utilizada uma variável binária associada à presença, ou não, da informação, que permite uma análise de frequência das informações divulgadas em cada segmento de mercado. $\mathrm{Na}$ Tabela 2, são apresentados os valores percentuais da frequência de divulgação para cada item analisado.

Tabela 2

\section{Frequência de divulgação - Por requisito (em \%)}

\begin{tabular}{|c|c|c|c|c|c|c|c|c|c|c|c|c|c|}
\hline \multirow{2}{*}{$\begin{array}{l}\text { Segmento } \\
\text { do mercado }\end{array}$} & \multicolumn{4}{|c|}{$\begin{array}{l}\text { 1. Informações } \\
\text { Simples e Diretas }\end{array}$} & \multicolumn{4}{|c|}{$\begin{array}{l}\text { 2. Informações } \\
\text { Qualitativas }\end{array}$} & \multicolumn{4}{|c|}{$\begin{array}{l}\text { 3. Informações } \\
\text { Detalhadas }\end{array}$} & \multirow{2}{*}{$\begin{array}{l}\text { Média } \\
\text { (sgmt) }\end{array}$} \\
\hline & A & B & C & D & E & $\mathrm{F}$ & G & H & 1 & J & K & L & \\
\hline Novo Mercado & 100,0 & 91,1 & 100,0 & 98,2 & 83,9 & 58,9 & 73,2 & 67,9 & 96,4 & 73,2 & 35,7 & 35,7 & 76,2 \\
\hline Nível 2 & 100,0 & 100,0 & 100,0 & 100,0 & 75,0 & 87,5 & 100,0 & 50,0 & 100,0 & 87,5 & 25,0 & 37,5 & 80,2 \\
\hline Nível 1 & 100,0 & 100,0 & 100,0 & 100,0 & 100,0 & 37,5 & 87,5 & 75,0 & 75,0 & 87,5 & 62,5 & 25,0 & 79,2 \\
\hline Tradicional & 100,0 & 100,0 & 100,0 & 100,0 & 68,2 & 27,3 & 77,3 & 59,1 & 77,3 & 63,6 & 50,0 & 31,8 & 71,2 \\
\hline Média (requisito) & 100,0 & 97,8 & 100,0 & 99,6 & 81,8 & 52,8 & 84,5 & 63,0 & 87,2 & 78,0 & 43,3 & 32,5 & 76,7 \\
\hline
\end{tabular}

Fonte: elaborado pelos autores.

A última coluna da Tabela 2 traz as frequências médias de divulgação quando considerado o segmento de mercado, e a última linha traz por requisito. No primeiro caso, observa-se que as maiores frequências médias foram dos segmentos especiais, enquanto a menor foi do Mercado Tradicional. Embora com pouca diferença, isso sugere que as empresas listadas nos segmentos de Governança Corporativa trazem para um maior o nível de divulgação das informações em notas explicativas. Na divulgação por requisito, destaca-se o primeiro grupo de informações com frequências médias superiores a 97\%, enquanto os dois outros blocos apresentam valores inferiores. Isso sugere que as informações mais simples ou gerais tendem a ser mais divulgadas que informações qualitativas ou detalhadas. 
No primeiro bloco, é possível observar um maior nível de divulgação de informações simples e diretas sobre as operações, em que: o nome (A) e a proporção da empresa adquirida (C) foram divulgados por todas as empresas; e o valor da contraprestação total (D) e a data (B) mostraram menores frequências no Novo Mercado. Nesse segmento, ocorreram cinco casos, sendo quatro divulgações de uma mesma empresa, em que a data foi considerada como não divulgada por não ter sido informado o dia da operação, apenas o mês e ano; e um caso, de outra empresa, em que não foi divulgado o valor total da contraprestação de forma explícita. Nos outros segmentos, a divulgação destes quatro itens completos foi realizada por todas as empresas.

Em relação ao segundo e terceiro blocos, as frequências médias por requisito de todos os itens foram menores que no primeiro, como mostra a última linha da Tabela 2. No Bloco 2, de informações qualitativas, as maiores frequências são das descrições do processo de aquisição do controle (G) e da empresa adquirida (E); e as menores são quanto aos motivos ou objetivos da aquisição (F) e quanto à fundamentação qualitativa do ágio ou da compra vantajosa $(\mathrm{H})$. Na descrição da empresa adquirida, foram encontradas informações principalmente relacionadas à localização geográfica, atividades operacionais e mercados atendidos. Quanto ao processo de aquisição de controle, muitas operações se deram por assinatura de contratos ou foram casos de combinações realizadas em estágios. A fundamentação qualitativa do ágio foi dada por aspectos relacionados a sinergias operacionais ou administrativas, economias de escala, valor do poder de negociação com financiadores, expectativas de lucratividade futura. A fundamentação da compra vantajosa foi dada por altos endividamentos e riscos de eventuais quebras de compromissos financeiros.

No Bloco 3, foram analisadas informações de caráter mais detalhista, relacionado a aspectos contábeis e financeiros da operação. Destaca-se uma maior frequência média para divulgação dos valores justos dos tipos mais relevantes de contraprestação (I) e o montante reconhecido das principais classes de ativos adquiridos e passivos assumidos (J). Os quesitos de receitas e resultados gerados pela adquirida desde a aquisição (K) e de estimativa das receitas e resultados desde o início do exercício (L) apresentaram menor frequência média de divulgação, não chegando à metade das observações totais.

Para uma visão mais conjunta sobre os tipos de informações e seu nível de divulgação de acordo com o segmento das empresas, é possível analisar as frequências de divulgação em blocos, conforme tratado na Tabela 3. Quando agrupadas, observa-se pela última linha da tabela que as informações simples e diretas sobre as operações, do Bloco 1, apresentam frequência média geral quase total, e que, conforme é aumentada a complexidade, a divulgação se mostra menor. Novamente ficam evidenciados os casos encontrados de não atendimento dos itens de data completa e valor do negócio nas divulgações do Novo Mercado, enquanto os outros segmentos apresentaram total atendimento a estes itens.

Para as informações qualitativas, do Bloco 2, os segmentos especiais mostram frequências entre 70 e $80 \%$ de divulgação, enquanto no Mercado Tradicional não chega a 60\%. Para o grupo das informações mais detalhadas, representadas no Bloco 3, os segmentos diferenciados apresentam frequências médias superiores a $60 \%$, pouco acima do Mercado Tradicional, com 55,7\%.

Tabela 3

Frequência de divulgação - Por bloco (em \%)

\begin{tabular}{lccc} 
Segmento do mercado & $\begin{array}{c}\text { 1. Informações } \\
\text { Simples e Diretas }\end{array}$ & $\begin{array}{c}\text { 2. Informações } \\
\text { Qualitativas }\end{array}$ & $\begin{array}{c}\text { 3. Informações } \\
\text { Detalhadas }\end{array}$ \\
\hline Novo Mercado & 97,3 & 71,0 & 60,3 \\
\hline Nível 2 & 100,0 & 78,1 & 62,5 \\
\hline Nível 1 & 100,0 & 75,0 & 62,5 \\
\hline Tradicional & 100,0 & 58,0 & 55,7 \\
\hline Média Geral & 99,3 & 70,5 & 60,2 \\
\hline
\end{tabular}

Fonte: elaborado pelos autores. 
O comportamento de maior nível de divulgação dos segmentos Nível 1 e Nível 2, superior ao Novo Mercado, pode ser decorrente de motivos não investigados nesta pesquisa, ou da baixa quantidade de empresas listadas e de operações divulgadas, produzindo um padrão não esperado para segmento. Com isso, como na investigação da hipótese principal da pesquisa buscou-se comparar o Novo Mercado em relação ao Mercado Tradicional, de forma complementar, foram agrupados também os segmentos especiais para comparação com o Mercado Tradicional.

$\mathrm{Na}$ análise das informações agregadas em blocos, percebe-se uma maior frequência de divulgação no Novo Mercado para as informações qualitativas, no Bloco 2, e detalhadas, no Bloco 3, quando comparado ao nível de divulgação no Mercado Tradicional. Já para o Bloco 1, relacionado a informações simples e diretas, a frequência de divulgação do Novo Mercado foi um pouco menor que o total nos outros segmentos, refletindo os casos de não divulgação de data completa e valor da contraprestação total mencionados na análise da Tabela 1. Essas considerações apontam para uma confirmação da hipótese principal da pesquisa, de que o Novo Mercado traz maior nível de divulgação de informações que o Mercado Tradicional, que se alinha ao resultado de Lanzana et al. (2006), que apontam a complementaridade da estrutura de governança e o nível de disclosure das empresas.

Como complemento às análises descritivas das frequências de divulgação, em abordagem estatística, foi aplicado o teste de Mann-Whitney, não paramétrico para amostras independentes. Com esse teste, foram inicialmente comparadas as frequências de divulgação das informações em nível geral e por blocos, entre os segmentos de Novo Mercado e Mercado Tradicional, conforme apresentado na Tabela 4. Posteriormente, como complemento, também foram comparados os três segmentos de listagem especial com o Mercado Tradicional.

Para a frequência média geral de divulgação, o resultado mostra não haver diferença entre os segmentos nem a $10 \%$ de significância estatística ( $\mathrm{p}$-valor $=0,290)$. Na análise por blocos de informações, os resultados do teste apontam para uma maior divulgação apenas para o Bloco 2, das informações qualitativas, ao nível de $5 \%$, mas não a $1 \%$ (p-valor = 0,022); e os Blocos 1, de informações diretas, e 3, de detalhes sobre a operação, apontam para um mesmo nível de divulgação entre os segmentos, mesmo a 10\% de significância estatística ( $\mathrm{p}$-valores $=0,112$ e 0,868, respectivamente).

Tabela 4

Resultados do Teste de Mann-Whitney para os segmentos Novo Mercado - NM e Mercado Tradicional - MT

\begin{tabular}{lcccc} 
& \multicolumn{4}{c}{ Blocos de Informações } \\
\cline { 2 - 5 } & Média Geral & {$[1]$} & {$[2]$} & {$[3]$} \\
\hline Mean Rank - NM & 41,18 & 38,32 & 43,00 & 38,84 \\
\hline Mean Rank - MT & 35,23 & 42,50 & 30,59 & 39,76 \\
\hline Sig. Asint. & 0,290 & 0,112 & 0,022 & 0,868 \\
\hline Conclusões (Sig. = 0,05) & NM = MT & NM $=$ MT & NM > MT & NM = MT \\
\hline
\end{tabular}

Fonte: elaborado pelos autores.

Pela última linha da Tabela 4, observa-se que o nível de divulgação geral não é considerado estatisticamente significativo, apontando para uma não confirmação da hipótese principal da pesquisa. É interessante comentar que no trabalho de Nakayama (2012), que observou as demonstrações financeiras de 2010, a presença da empresa na listagem diferenciada nos segmentos Nível 2 ou Novo Mercado foi tratada como variável binária explicativa para o nível de disclosure do índice elaborado pelo pesquisador, e também não apresentou significância estatística ( $\mathrm{p}$-valor $=0,374$ ). 
Uma vez que os Níveis 1 e 2 de governança mostraram maiores frequências de divulgação que o Novo Mercado, como complemento, realizou-se o mesmo teste estatístico, comparando as empresas listadas nos segmentos especiais como um único conjunto em relação ao Mercado Tradicional. Para a média geral, encontrou-se um p-valor de 0,185; para o Bloco 1, de 0,164, para o Bloco 2, de 0,009; e para o 3 , de 0,853 . Dessa forma, mesmo considerando a listagem diferenciada como um todo, não se encontraram diferenças estatísticas entre os níveis de divulgação geral entre os segmentos. Quanto às informações separadas por tipo, apenas as do Bloco 2, descritivas, apresentaram diferença significativa ao nível de 1\%, enquanto as mais simples e as detalhistas mantiveram-se iguais entre os segmentos, mesmo a $10 \%$ de significância. Dessa forma, reforça-se a percepção de que não se encontram evidências estatísticas significativas do nível de divulgação de informações relacionadas ao tipo de listagem.

Então, embora a análise descritiva das frequências de divulgação aponte para um nível superior de informação relacionado aos segmentos diferenciados, tais resultados não são corroborados pela abordagem estatística realizada, não confirmando a hipótese principal da pesquisa. Em última instância, conclui-se que, apesar de se mostrar superior em níveis absolutos para o ano de 2012, tais diferenças podem estar associadas a fatores estocásticos. Sob estas considerações, conclui-se que a hipótese principal da pesquisa não se confirma, pois não se pode afirmar com segurança que o nível de divulgação das informações sobre combinações de negócios no Novo Mercado seja superior ao Mercado Tradicional.

Esse resultado também pode refletir que a própria listagem em segmentos especiais da bolsa não seria suficiente para identificar maior ou menor nível de transparência de informações ao mercado, nem a evidenciação de um aprendizado diferenciado, contrariando o argumento que fundamentou a hipótese principal e a motivação da pesquisa. É possível que empresas do Mercado Tradicional não realizem a adesão aos segmentos especiais por motivos não relacionados à transparência, de forma que adotam uma política de divulgação semelhante à dos segmentos especiais apesar de não estarem neles listados. Ainda assim, vale considerar os achados de Lanzana et al. (2006), que observaram maior disclosure relacionado à Governança Corporativa, elaborando um índice próprio a partir de variáveis relacionadas à estrutura de propriedade e conselho de administração.

Por outro lado, para as informações descritivas, houve diferenças significativas no nível de divulgação relacionado à listagem em segmentos especiais. Essa evidência pode apontar que tais informações, de caráter mais qualitativo, estão mais alinhadas a informações voluntárias divulgadas pelas empresas, conforme os achados de estudos anteriores aplicados ao mercado brasileiro, como Mendes-da-Silva et al. (2009) e Murcia e Santos (2009).

Como hipótese adicional, considerou-se que seria encontrado maior nível de divulgação de informações mais simples, e menor conforme mais complexos fossem os requisitos. Como procedimento semelhante, convém uma análise dos itens agrupados em seus respectivos blocos representados na Tabela 3, com uma abordagem estatística complementar, apresentada na Tabela 5.

$\mathrm{Na}$ Tabela 3, quando comparados os blocos horizontalmente, ou seja, para cada segmento de mercado, é possível observar que as informações do Bloco 1, simples e diretas, mostram frequências maiores que as do Bloco 2, qualitativas; e que, por sua vez, são maiores que as do Bloco 3, sobre os detalhes das operações, em todos os quatro segmentos. O mesmo comportamento é refletido na frequência média geral dos blocos, como resume a última linha da tabela. Essa observação indica haver um maior nível de atendimento a requisitos de divulgação que sejam mais simples, seguido de informações de caráter descritivo, e menor para detalhes sobre a operação, apontando para a confirmação da hipótese adicional.

Em abordagem estatística, foi aplicado o teste de Wilcoxon, não paramétrico para amostras emparelhadas. As diferenças das frequências de divulgação se mostraram estatisticamente significativas entre os três blocos de informações analisados, mesmo a 1\% de significância. Pelos resultados apresentados na Tabela 5, é possível observar que as informações do Bloco 1 são as mais divulgadas e as do Bloco 3, as menos. 
Tabela 5

Resultados do Teste de Wilcoxon para os blocos de informações

\begin{tabular}{lccc} 
& \multicolumn{3}{c}{ Diferenças entre os Blocos de Informações } \\
\cline { 2 - 4 } & {$[1]-[2]$} & {$[1]-[3]$} & [2] - [3] \\
\hline Positive Ranks & 71 & 71 & 43 \\
\hline Negative Ranks & 0 & 23 & 22 \\
\hline Ties & 23 & 0,000 & 29 \\
\hline Sig. Asint. & 0,000 & {$[1]>[3]$} & 0,004 \\
\hline Conclusões (Sig. $=0,05)$ & {$[1]>[2]$} & & {$[2]>[3]$} \\
\hline
\end{tabular}

Fonte: elaborado pelos autores.

De forma geral, observa-se que as informações mais simples e diretas apresentam maior frequência de divulgação e as detalhadas, menor nível. Este efeito é consistente com o que observa Bachir (2013), para os anos de 2010 e 2011, "à medida que a complexidade e a relevância das informações solicitadas aumentam, reduz-se o nível de evidenciação de tais informações em notas explicativas".

Então, tanto a análise descritiva como a estatística confirmam a hipótese adicional da pesquisa, de que conforme maior a complexidade das informações requeridas, menor seu o nível de divulgação. Portanto, pode-se afirmar que as informações sobre combinações de negócios divulgadas em notas explicativas foram mais divulgadas, conforme maior sua simplicidade, em menor nível, conforme sua complexidade.

Sob o argumento da curva de aprendizagem, pode-se considerar que itens mais complexos demorariam mais a serem plenamente divulgados pelas empresas e que, conforme se passarem os exercícios sociais, tais requisitos apresentariam maior nível de divulgação. Além disso, questões relacionadas ao custo-benefício da divulgação da informação podem ser relevantes para publicação de informações de caráter mais detalhista, de maneira que há possibilidade de que as empresas não dispensem recursos na captação, elaboração e divulgação de informações mais complexas.

Essa constatação pode indicar, ainda, que as empresas evitam publicar informações mais estratégicas ou reveladoras, tal qual observaram Aillón, Silva, Pinzan e Wuerges (2013), em relação a informações por segmentos. Os autores analisam as informações gerenciais publicadas em notas explicativas, e concluem que existe uma tendência de ocultá-las, limitando análises de longo prazo e decisões de investimento da companhia. De forma semelhante, Shalev (2009) sugere haver certa escolha no nível de divulgação de informações conforme os interesses da companhia, conforme identificou no mercado americano para combinações de negócios.

Como aprofundamento da abordagem estatística, também foram comparadas as diferenças entre os blocos, isolando os segmentos de mercado. Nestes casos, as informações mais simples apresentaram frequências estatisticamente superiores às dos outros tipos, em todos os segmentos de mercado ( $\mathrm{p}$-valores $<0,001)$. Já as informações descritivas e detalhistas mostraram menores diferenças estatísticas, sendo significativas a 5\% no Novo Mercado ( $\mathrm{p}$-valor = 0,015), mas não nos segmentos de Nível 1 e 2 (p-valores $=0,102$ e 0,163, respectivamente) e nem para o Mercado Tradicional ( $\mathrm{p}$-valor $=0,540)$. Esses resultados condizem com a observação direta da Tabela 1, de que as informações mais simples são as mais divulgadas em todos os segmentos.

Nesse contexto, também é relevante destacar que a listagem especial mostrou diferenças na divulgação das informações menos imediatas. Esse efeito é, notadamente, captado tanto pelos resultados dos testes de Mann-Whitney, na comparação das frequências de divulgação das informações descritivas do Novo Mercado em relação ao Mercado Tradicional, como também pelo teste de Wilcoxon, nas diferenças entre as informações descritivas e detalhistas para o Novo Mercado, apresentando significância estatística, mas não para o Mercado Tradicional. 
Assim, embora não se possa afirmar que a listagem especial promova um maior nível de divulgação de informações como um todo, ficou evidenciado que para as informações qualitativas as empresas dos segmentos diferenciados apresentaram maior nível de divulgação que as do Mercado Tradicional. Com isso, sugere-se maior sensibilidade quanto ao tipo de informação divulgada relacionada ao segmento de mercado.

Sob o argumento de que as informações divulgadas requerem estrutura para preparo, e que empresas maiores dispõem de melhor estrutura e que podem arcar com os custos de elaboração e captação das informações a serem divulgadas, buscou-se em análise adicional, o levantamento do nível de divulgação relacionado ao tamanho das empresas, mensurado pelo ativo total. Para isso, foram calculadas as correlações entre as frequências de divulgação e os ativos totais, para o ano de 2012, tanto em nível geral como para cada bloco de informações, assim como para a amostra como um todo e estratificada quanto a cada segmento de listagem. Na Tabela 6, são apresentados os valores calculados das correlações das frequências de divulgação de cada grupo de informações, conforme seu tipo e segmento de mercado das empresas, em relação ao Ativo Total das empresas, como medida de seu tamanho. Em relação às informações do Bloco 1, de informações diretas, para os segmentos de Níveis 1 e 2 e Mercado Tradicional, não se aplica o cálculo da correlação com o tamanho, pois houve divulgação plena dos requisitos pelas empresas.

Tabela 6

Correlações de cada grupo de informações em relação ao Ativo Total das empresas

\begin{tabular}{lcccc}
\multicolumn{1}{c}{$\begin{array}{c}\text { Segmento } \\
\text { do mercado }\end{array}$} & $\begin{array}{c}\text { 1. Informações } \\
\text { Simples e Diretas }\end{array}$ & $\begin{array}{c}\text { 2. Informações } \\
\text { Qualitativas }\end{array}$ & $\begin{array}{c}\text { 3. Informações } \\
\text { Detalhadas }\end{array}$ & Nível Geral \\
\hline Novo Mercado & 0,046 & 0,173 & 0,204 & $0,245^{*}$ \\
\hline Nível 2 & - & $-0,218$ & $-0,039$ & $-0,161$ \\
\hline Nível 1 & - & $-0,471$ & 0,045 & $-0,311$ \\
\hline Tradicional & - & 0,085 & 0,286 & 0,255 \\
\hline Total das empresas & $\mathbf{0 , 0 3 1}$ & $\mathbf{0 , 1 4 0}$ & $\mathbf{0 , 1 6 8}$ & $\mathbf{0 , 1 9 7 ^ { * }}$ \\
\hline
\end{tabular}

* Correlação é significante ao nível de 0,10

Fonte: elaborado pelos autores.

Comparadas ao valor crítico pertinente, definido pela quantidade de combinações totais e para cada segmento de mercado divulgadas, ao nível de 5\%, nenhuma das correlações se mostrou significativa; já ao nível de $10 \%$, apenas a divulgação geral mostrou correlação significativa e positiva com o tamanho das empresas para o grupo total das empresas e para o segmento do Novo Mercado (p-valores $=0,056 \mathrm{e}$ 0,069, respectivamente). Observa-se, portanto, fraca evidência da relação entre tamanho e nível de divulgação, concluindo-se que empresas maiores não necessariamente divulgaram mais informações no Mercado Tradicional, mas com indícios de maior sensibilidade ao tamanho das empresas na divulgação de informações em nível geral para o mercado como um todo e no Novo Mercado.

A própria natureza das informações analisadas convém ser discutida. Por se tratarem de informações de caráter obrigatório, sua não divulgação denota um atendimento apenas parcial à normatização como um todo, independente dos compromissos adicionais assumidos nos segmentos especiais de listagem. Isso reflete uma questão que pode estar relacionada mais à compliance do que ao disclosure das empresas. Este comportamento é criticado por Assis et al. (2013): "Os preparadores das demonstrações financeiras precisam evidenciar no mínimo o que está disposto no CPC 15 .... É inconcebível que as empresas se omitam em divulgar itens importantes", declarando esperar o amadurecimento dos preparadores e auditores, aumentando o nível de divulgação. Em Nakayama (2012) e Nakayama e Salotti (2014), é analisado o primeiro ano de aplicação da norma, em 2010, e os autores julgam que o nível de divulgação encontrado não foi alto devido à novidade da legislação, mas alertam que sem um papel ativo por parte dos reguladores, "corre-se o risco de não avançar na melhoria do nível de informação divulgada, uma 
vez que norma sem enforcement pode ser entendida apenas como uma sugestão". Bachir (2013) também atribui ao baixo atendimento encontrado a norma ser recente, reforçando que "as informações divulgadas nas demonstrações financeiras pelas companhias, referentes às Combinações de Negócios, são muito importantes para que investidores e analistas possam entender o que de fato se pode esperar para o futuro após a aquisição".

\section{Conclusões}

Esta pesquisa teve como objetivo investigar o nível de divulgação das informações de combinações de negócios nas demonstrações financeiras das empresas de capital aberto listadas na Bovespa, em relação ao ano de 2012, considerando os diferentes segmentos de mercado. Pela metodologia aplicada a esta pesquisa, observou-se o atendimento a itens incondicionais do CPC 15 (R1) quanto à divulgação em notas explicativas. Os itens verificados foram elaborados a partir do pronunciamento técnico, e de considerações sobre trabalhos semelhantes realizados, especialmente os de Bachir (2013) e Nakayama (2012); e foram agrupados quanto ao tipo, em três blocos de informações: simples e diretas, qualitativo-descritivas, e de detalhamento contábil-financeiro sobre as operações divulgadas.

A motivação da pesquisa se fundamenta nas conclusões de estudos anteriores sobre o tema, de que haveria certa curva de aprendizado. A hipótese principal se baseia, principalmente, no argumento de que as empresas com níveis diferenciados de Governança Corporativa possuem maior compromisso com a divulgação de informações mais transparentes e abrangentes, de forma que as divulgações no Novo Mercado trariam maior nível de informação que no Mercado Tradicional. Adicionalmente, testou-se a hipótese de que as informações seriam mais divulgadas, conforme mais simples fosse a requisição normativa, e menos, conforme maior a complexidade.

$\mathrm{Na}$ análise das informações, percebe-se uma maior frequência de divulgação no Novo Mercado para as informações qualitativas quando comparado ao Mercado Tradicional. Já, para os blocos de informações mais simples e mais detalhistas não foram encontradas diferenças significativas de divulgação entre os segmentos. Esse resultado pode refletir que o aprendizado apontado por Nakayama (2012), Assis et al. (2013) e Bachir (2013) e Nakayama e Salotti (2014) possa já ser percebido para as informações descritivas. Pode-se considerar que, para tais informações, que possuem caráter mais descritivo, as empresas mostraram comportamento semelhante à divulgação voluntária investigada por estudos de disclosure, em comparação a informações mais diretas ou mais complexas, para as quais o comportamento das empresas não apresenta diferenciação associado ao segmento de listagem.

Para conclusões mais precisas a respeito da revelação de informações, é possível a observação em painel, conforme se passarem os períodos financeiros, ou em conjunto com outros itens publicados, semelhante a Hogdon et al. (2009). Essa seria uma forma de investigar se é o caso de uma escolha das empresas em não divulgar informações consideradas estratégicas, conforme apontado por Aillón et al. (2013), ou confirmar uma curva de aprendizado relacionada ao tempo, conforme argumentado em pesquisas anteriores. Outra forma de aprimorar esta pesquisa seria trabalhar com uma relação de variáveis mais elaborada para segregação das empresas quanto à governança corporativa ou mais associada a fatores considerados determinantes de transparência.

Por fim, pelo aprofundamento das comparações dos blocos das informações e dos segmentos, foram encontrados indícios de maior sensibilidade ao tipo de informação divulgada relacionada ao segmento de mercado. Espera-se contribuir, apontando a possibilidade de agrupamento quanto ao tipo das informações requisitadas pelas normas em geral, relacionando-as aos compromissos adicionais assumidos pela adesão aos segmentos especiais da Bovespa, ou a outros indicadores de transparência. 


\section{Referências}

Aillón, H. S., Silva, J. O., Pinzan, A. F., \& Wuerges, A. F. E. (2013). Análise das informações por segmento: divulgação de informações gerenciais pelas empresas brasileiras. Revista Contemporânea de Contabilidade, 10(9), pp. 33-48. doi: HTTP://dx.doi.org/10.5007/2175-8069

Assis, A. I. R., Marinho, S. L., Silva, T. D., \& Andrade, M. E. M. (2013, julho). Nível de divulgação das combinações de negócios. Anais do Congresso USP de Iniciação Científica e Contabilidade, São Paulo, SP, Brasil, 10.

Bachir, O. A. A. (2013). Um estudo sobre o nível de evidenciação nas demonstrações financeiras em casos de combinações de negócios no Brasil nos anos de 2010 e 2011. Dissertação de mestrado, Fundação Getúlio Vargas, São Paulo, SP, Brasil. Recuperado de http://bibliotecadigital.fgv.br/dspace/bitstream/handle/10438/10898/Bachir,\%20Otavio_Finan\%C3\%A7as_Dissetra\%C3\%A7\%C3\%A3o_Final_07.06.2013.pdf.

Bolsa de Valores de São Paulo. (2013a). Novo mercado. Recuperado em 14 setembro, 2013 de http://www. bmfbovespa.com.br/pt-br/servicos/solucoes-para-empresas/segmentos-de-listagem/novo-mercado.aspx?idioma $=$ pt-br.

Bolsa de Valores de São Paulo. (2013b). O que são segmentos de listagem. Recuperado em 14 setembro, 2013 de http://www.bmfbovespa.com.br/pt-br/servicos/solucoes-para-empresas/segmentos-de-listagem/o-que-sao-segmentos-de-listagem.aspx?idioma=pt-br.

Comitê de Pronunciamentos Contábeis. (2011). Pronunciamento Técnico CPC 15 (R1) - Combinação de Negócios. Recuperado em 19 agosto, 2013 de http://www.cpc.org.br/pdf/CPC15_R1_20062011.doc.

Fávero, L. P., Belfiore, P., Silva, F. L. da, \& Chan, B. L. (2009). Análise de dados - modelagem multivariada para tomada de decisões. Rio de Janeiro: Campus/Elsevier.

Instituto Brasileiro de Governança Corporativa. (2009). Código das melhores práticas de governança corporativa. (4a ed.). Recuperado em 14 setembro, 2013 de http://www.ibgc.org.br/Download. aspx $?$ Ref $=$ Codigos $\&$ CodCodigo $=47$.

Instituto Brasileiro de Governança Corporativa. (2013). Governança no Brasil. Recuperado em 14 setembro, 2013 de http://www.ibgc.org.br/Secao.aspx?CodSecao=20.

Hodgdon, C., Tondkar, R. H., Harless, D. W., \& Adhikari, A. (2008). Compliance with IFRS disclosure requirements and individual analysts' forecast errors. Journal of International Accounting, Auditing and Taxation 17(1), pp. 1-13. doi: 10.1016/j.intaccaudtax.2008.01.002.

IASB - International Accounting Standards Board (2011) IFRS 3 - Business Combinations. Recuperado em 19 agosto, 2013, de http://www.iasplus.com/en/standards/ifrs/ifrs3.

Iudícibus, S., Martins, E., Gelbcke, E. R. \& Santos, A. (2010). Manual de Contabilidade Societária (1ª ed.). São Paulo: Atlas.

Lanzana, A. P., Silveira, A. M., \& Famá, R. (2006, setembro). Existe relação entre disclosure e governança corporativa no Brasil? Anais do Encontro Nacional da Associação Nacional de Pós-Graduação e Pesquisa em Administração, Salvador, BA, Brasil, 30.

Leuz, C. (2006). Cross listing, bonding and firms' reporting incentives: A discussion of Lang, Raedy and Wilson (2006). Journal of Accounting and Economics 42(1-2), pp.285-299. doi: 10.1016/j.jacceco.2006.04.003.

Mendes-da-Silva, W., Ferraz-Andrade, J. M., Famá, R., \& Maluf, J. A. Filho (2009). Disclosure via website corporativo: um exame de informações financeiras e de governança no mercado brasileiro. Revista de Administração de Empresas 49(2), pp. 190-205. HTTP://dx.doi.org/10.1590/S0034759020000000.200006 
Murcia, F. D., Santos, A. (2009). Fatores determinantes no nível de disclosure voluntário das companhias abertas no Brasil. REPeC - Revista de Educação e Pesquisa em Contabilidade 3(2), pp. 72-95.

Nakayama, W. K. (2012). Divulgação de informações sobre operações de combinação de negócios na vigência do pronunciamento técnico CPC 15. Dissertação de mestrado, Universidade de São Paulo, São Paulo, SP, Brasil. Recuperado de http://www.teses.usp.br/teses/disponiveis/12/12136/tde-06122012161505/publico/WilsonKazumiNakayamaVC.pdf.

Nakayama, W. K., \& Salotti, B. M. (2014). Fatores Determinantes do Nível de Divulgação de Informações sobre Combinações de Negócios com a Entrada em Vigor do Pronunciamento Técnico CPC 15. Revista Contabilidade \& Finanças - USP 25(66), pp. 267-280. doi: 10.1590/1808-057x20141126

Raupp, F. M., \& Beuren, I. M. (2010). Metodologia da pesquisa aplicável às ciências sociais. In I. M. Beuren (Org.) Como elaborar trabalhos monográficos em Contabilidade: teoria e prática. $3^{\mathrm{a}} \mathrm{ed} ., \mathrm{pp} .76-$ 97. São Paulo: Atlas.

Rabelo, S. S. T., Rogers, P., Ribeiro, K. C. S., \& Securato, J. R. (2007). Análise comparativa de carteiras com práticas de governança corporativa inferiores e superiores. Revista de Gestão USP 14(Edição Especial), pp. 1-16.

Shalev, R. (2009). The information content of business combination disclosure level. The Accounting Review 84(1), pp. 239-270. doi: 10.2308/accr.2009.84.1.239.

Sirqueira, A. B., Kalatzis, A. E. G., \& Toledo, F. M. B. (2007). Boas práticas de governança corporativa e otimização de portfólio: Uma análise comparativa. Economia 8(2), pp. 521-544. 